\title{
Experimental analysis and constitutive modelling of steel of A-IIIN strength class
}

\author{
Leopold Kruszka $^{1, a}$ and Jacek Janiszewski ${ }^{2}$ \\ ${ }^{1}$ Military University of Technology, Faculty of Civil Engineering and Geodesy, 2 Gen. Sylwester Kaliski St., 00-908 \\ Warsaw, Poland \\ ${ }^{2}$ Military University of Technology, Faculty of Mechatronics and Aviation, 2 Gen. Sylwester Kaliski St., 00-908 \\ Warsaw, Poland
}

\begin{abstract}
Fundamentally important is the better understanding of behaviour of new building steels under impact loadings, including plastic deformations. Results of the experimental analysis in wide range of strain rates in compression at room temperature, as well as constitutive modelling for and B500SP structural steels of new A-IIIN Polish strength class, examined dynamically by split Hopkinson pressure bar technique at high strain rates, are presented in table and graphic forms. Dynamic mechanical characteristics of compressive strength for tested building structural steel are determined as well as dynamic mechanical properties of this material are compared with 18G2-b steel of A-II strength class, including effects of the shape of tested specimens, i.e. their slenderness. The paper focuses the attention on those experimental tests, their interpretation, and constitutive semi-empirical modelling of the behaviour of tested steels based on Johnson-Cook's model. Obtained results of analyses presented here are used for designing and numerical simulations of reinforced concrete protective structures.
\end{abstract}

\section{Introduction}

Examining the behaviour of structural construction steels in a wide range of deformation rates is important for solving the problems of ballistic impacts and penetrations at high-speeds, the dynamics of destruction and the safety of reinforced concrete and steel structures of protective and defensive buildings exposed to exceptional impacts. Nowadays, contemporary protection structures constitute neuralgic elements of critical infrastructure, in particular of public buildings and important engineering structures. These structures are designed to reduce the effects of a terrorist attack using both explosive materials and projectiles on the protected building structures and prevent the objects from construction disaster. The calculation of the ultimate limit state and usability of these supporting structures of buildings to dynamic loads using computer methods require knowledge of the constitutive equations describing the behaviour of the used construction materials. Constitutive equations even in a simplified form as a rule contain a number of model and material parameters to be determined experimentally.

Nowadays, for the design and construction of modern defensive and protective structures, new constants B500SP and St3SY-b-500 in the highest A-IIIN strength class are used. Their basic static properties by standards are given in the table No 1.

Since these steels have been recently introduced to the practice of engineering in civil engineering, in the available literature, there is no data on both the dynamic mechanical properties of these materials and their material

\footnotetext{
${ }^{a}$ Corresponding author: 1 kruszka@wat.edu.pl
}

Table 1. Static mechanical properties of structural steels B500SP and St3SY-b-500.

\begin{tabular}{|l|c|}
\hline The initial yield point $\left[\mathrm{N} / \mathrm{mm}^{2}\right]$ & 500 \\
\hline Tensile strength $\left[\mathrm{N} / \mathrm{mm}^{2}\right]$ & 575 \\
\hline $\begin{array}{l}\text { Modulus of longitudinal } \\
\text { elasticity [GPa] }\end{array}$ & 200 \\
\hline Standards & $\begin{array}{r}\text { PN-H 93220:2006, } \\
\text { PN-EN 0080:2005(U) }\end{array}$ \\
\hline
\end{tabular}

and model constants for any constitutive equation in a wide range of strain rates. As shown by previous studies $[1,2]$, for most metals and their alloys, differences in their behaviour during static and dynamic deformations are so clear that the results of static tests cannot be used to analyse and solve dynamic problems. Hence, there is an increase in demand for comprehensive experimental studies, especially for the dynamic properties of modern structural construction steels.

Experimental studies of the behaviour of the structural steel of B500SP and, for comparison purpose, 18G2-b steel of A-II strength class during the uniaxial stress state compression at high speeds of deformation were carried out using the compression Hopkinson bar test technique. The end result of this research work, having the aspect of application, is the proposed Johnson-Cook model for the given steels, which is widely used in the computer codes for the numerical analysis of engineering structures dynamically loaded. It should be noted that the design issues of protective structures and strengthening of elements of supporting structures of public buildings sensitive to the terrorist attacks, belong to "the engineering combat against terrorism" [3].

This is an Open Access article distributed under the terms of the Creative Commons Attribution License 4.0, which permits unrestricted use, distribution, and reproduction in any medium, provided the original work is properly cited. 


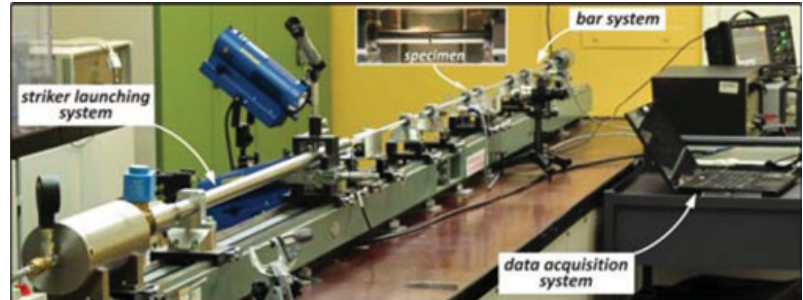

Figure 1. Compression split Hopkinson pressure bar used in investigations.

\section{Static and dynamic strength testing procedure}

To provide base-line material properties, materials compression strength tests under quasi-static loading were carried out. Quasi-static compression tests were performed on MTS Criterion 45 testing machine using specimens with $9 \mathrm{~mm}$ in diameter and 3,6 and $9 \mathrm{~mm}$ length. The strain-rate was maintained at $10^{-3} \mathrm{~s}^{-1}$. Material samples for both quasi-static and dynamic compression strength tests were machined from the same bars with diameter of $12 \mathrm{~mm}$.

A classical compression split Hopkinson pressure bar was applied to studied high-strain-rate mechanical response of given steels. The apparatus presented in Fig. 1 consists mainly of a striker launching system (air pressure gun), a striker, an input bar, an output bar (bar system), a velocity measuring device and a computer-controlled highfrequency data acquisition system.

The input bar and the output bar were $1218 \pm$ 0, $25 \mathrm{~mm}$ each long, while the striker length was $200 \pm$ $0,05 \mathrm{~mm}$. Both the bars and the striker had a common diameter of $12.05 \mathrm{~mm}$ and were made of commercial maraging steel grade 350, which was heat treated to guarantee high strength property of bars (nominal quasistatic yield strength $R_{0.2}=2320 \mathrm{MPa}$, Young modulus $E=190,6 \mathrm{GPa}$, sound speed $C_{o}=4866 \mathrm{~m} / \mathrm{s}$ ). Each bars were supported by 4 linear bearing stands, which were mounted on optical bench allowing precise alignment of the bars system.

The elastic deformation signals in the input and output, transmitted bars were captured using pair of strain gages attached symmetrically on the opposite surfaces of the bars and in theirs middle length. The strain gages were connected to the opposite legs of the Wheatstone bridge, which was a typical full bridge configuration. In the other legs of the tensometer bridge, the dummy resistors were mounted, which resistance matched with the strain gages resistance. The typical electrical strain gages of $1.6 \mathrm{~mm}$ gage length were used (CEA-13-062UW-350, Vishay Micro Measurements). The amplified signals of the strain gages were recorded at a frequency of $1 \mathrm{MHz}$ with the use of a signal conditioning unit (SGA-0B V5 Wheatstone bridge with signal conditioning amplifiers, ESA Messtechnik) and LeCroy WJ354A high-speed digital oscilloscope (data acquisition system).

In order to achieve an appropriate loading condition for high strain rate tests (e.g. stress equilibrium) a $4 \mathrm{~mm}$
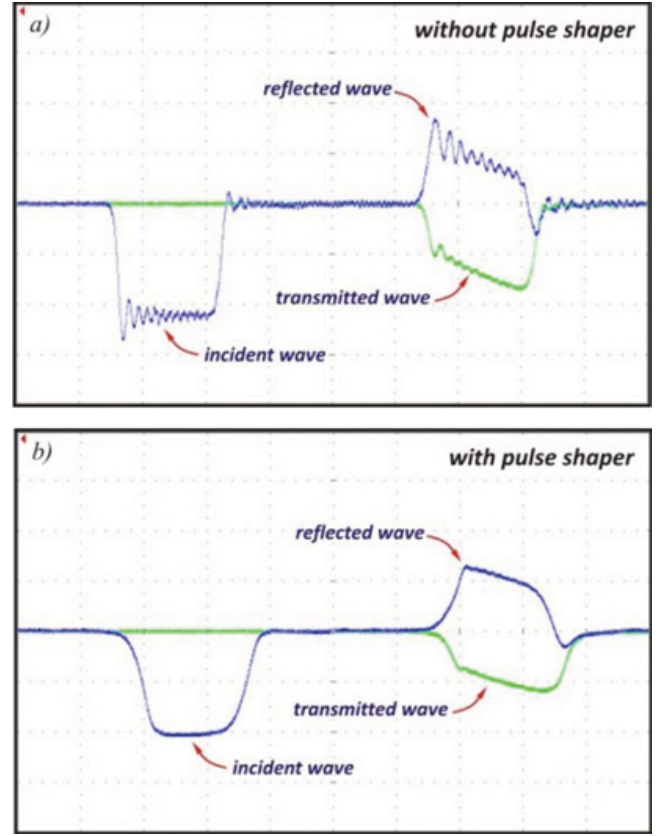

Figure 2. Comparison waves profiles obtained during Hopkinson experiments without (a) and with $0.3 \mathrm{~mm}$ thick wave pulse shaper (b).

diameter wave pulse shapers made of Cu-ETP copper sheet were usually used. The wave pulse shapers were manufactured from copper sheet with the use of sheet metal punching technique. In dependence on impact velocity of striker bar, the thickness of pulse shaper was $0.1,0.2,0.3$ and $0.4 \mathrm{~mm}$, respectively. For the example, waves profiles obtained for dynamic experiments without and with pulse shaper were presented in Fig. 2.

The high-strain-rate investigations were carried out on specimens with different slenderness $(L / D$ ratio, where $L$ and $D$ - length and diameter of specimen), which was 0.25 , $0.5,0.75$ and 1 , respectively. As a consequence, influence of specimen slenderness on plastic flow stress was also estimated. At least three dynamic tests were performed for each specimen geometry.

\section{Results and discussion}

\subsection{Mechanical response of tested structural steels}

Compilation of the quasi-static and dynamic strength tests for different slenderness of specimen is presented in Fig. 3. It can be seen clearly a minor impact of specimen slenderness on true stresses determined at 0.05 strain. Only in the case of specimens with slenderness of 0.25 it was found higher level of plastic flow stresses for both type of steels in comparison to other specimen slendernesses. Therefore further considerations on obtained results were made without taking into account of experimental data for specimens with the 0.25 slenderness.

On the basis of results presented in Fig. 3 and also in Fig. 4, it is observed a significant difference in mechanical strength for both tested materials. The B500SP steel is characterized by higher plastic flow stress than 18G2-b 
a)

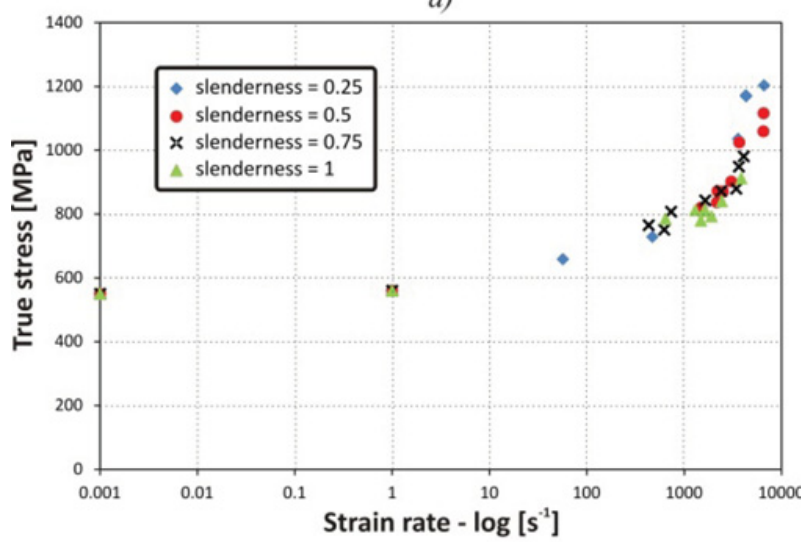

b)

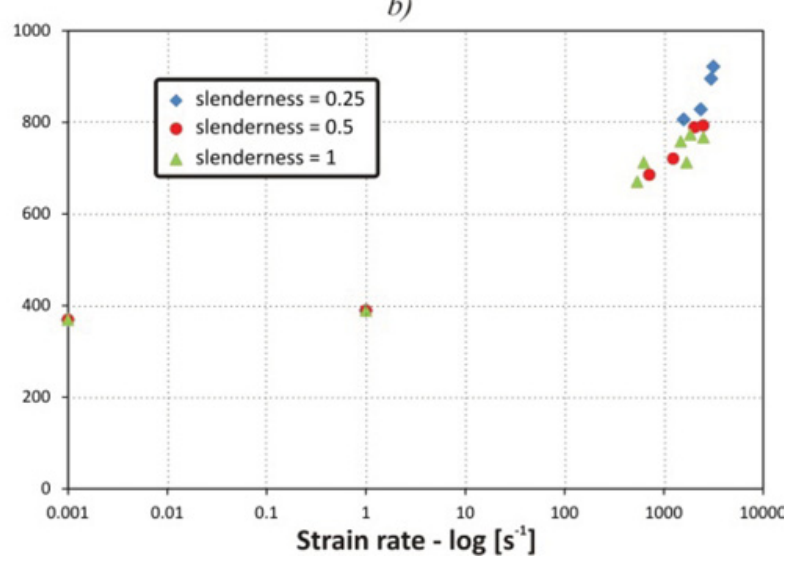

Figure 3. Specimen slenderness influence on plastic stress flow of the B500SP steel (a) and the 18G2-b steel (b) under different loading conditions.

steel both under static and dynamic loading conditions. The true stresses at small strains for B500SP steel are about $200 \mathrm{MPa}$ higher than ones for 18G2-b steel. However, for strains above 0.15 , differences in stresses decreases to about $100 \mathrm{MPa}$. Figure 4 shows also that character of stress changes is slightly variant: the original peak of stress for B500SP steel has oscillating nature, whereas in case of second structural steel the beginning of plastic flow seems to be smooth. Moreover, it was found the B500SP steel has got similar strain hardening sensitivity to the 18G2-b steel. In turn, strain rate sensitivity of the B500SP steel seems to be lower in comparison to $18 \mathrm{G} 2$-b steel. It is proved by results presented both in Fig. 4 and especially in Fig. 5. For quasi-static and moderate range of strain rate, B500SP steel is insensitive to strain rate, whereas 18G2b steel demonstrates modest strain rate sensitivity. Above strain rate level of $10^{3} \mathrm{~s}^{-1}$, flow stress increase for B500SP steel seems to be also relatively smaller than for 18G2-b steel.

\subsection{Determination of Johnson-Cook constitutive model parameters}

In order to assess the Johnson-Cook materials parameters for tested steels, the experimental data was fit to the

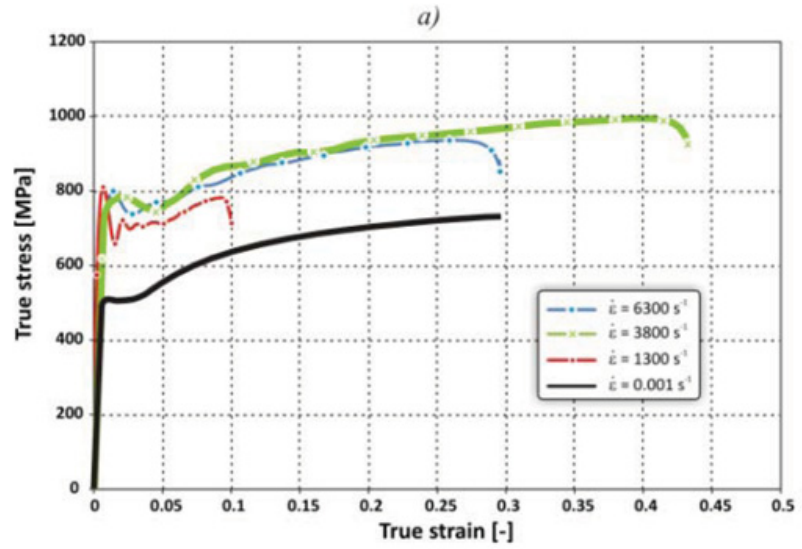

b)

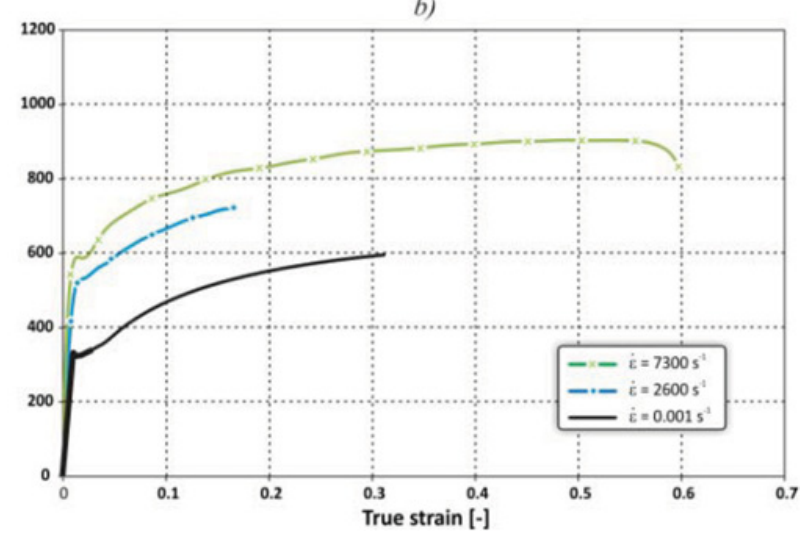

Figure 4. Comparison of stress-strain curves of the B500SP (a) and the 18G2-b steel (b) under different loading conditions.

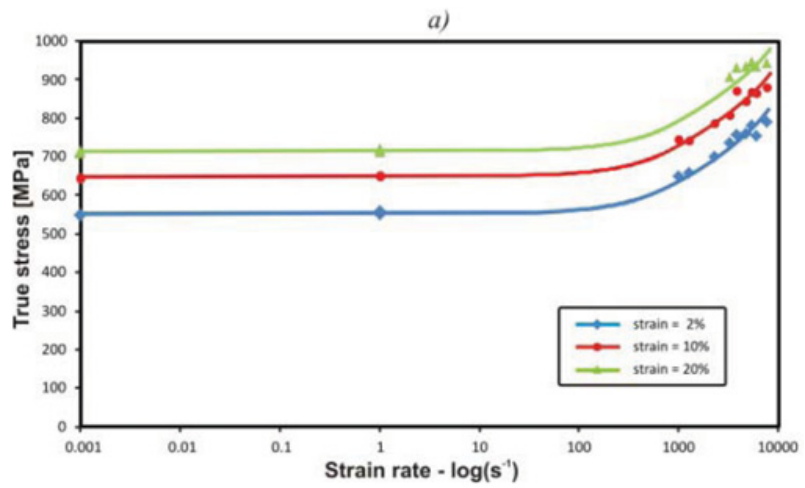

b)

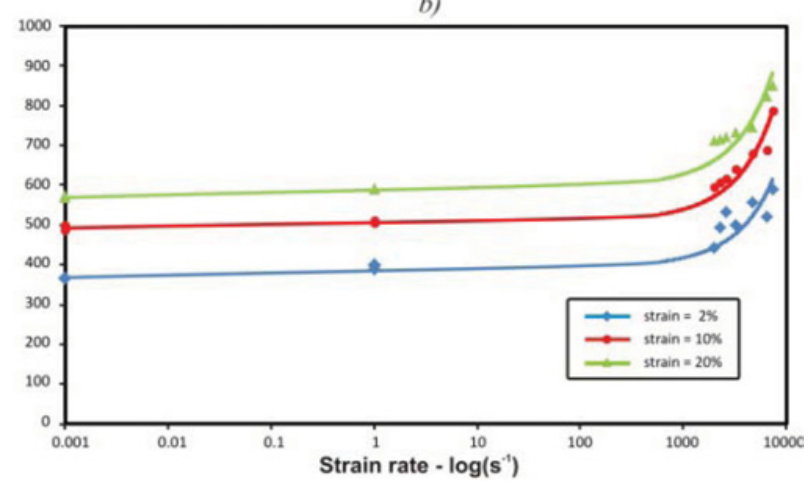

Figure 5. Flow stress strain rate sensitivity at $2 / 10 / 20 \%$ true plastic strain for B500SP (a) and 18G2-b (b) steels. 
Table 2. Johnson-Cook constitutive model parameters for B500SP and 18G2-b steels.

\begin{tabular}{|c|c|c|c|c|}
\hline Steel & $\boldsymbol{A}[\mathbf{M P a}]$ & $\boldsymbol{B}[\mathrm{MPa}]$ & $\boldsymbol{n}$ & $\boldsymbol{C}$ \\
\hline 18G2-b & 340 & 625 & 0.40 & 0.024 \\
\hline B500SP & 530 & 820 & 0.49 & 0.013 \\
\hline
\end{tabular}

simplified Johnson-Cook constitutive model (Eq. (1)) using a least-squares nonlinear regression procedure (genfit function) in Mathcad software.

$$
\sigma=\left(A+B \varepsilon^{n}\right)(1+C \ln (\dot{\varepsilon}))
$$

where: $A, B, n$ and $C$ are material constants. $A$ is the yield stress for $\dot{\varepsilon}_{\mathrm{c}}=1 \mathrm{~s}^{-1}, B$ and $n$ represents the strain hardening, $C$ is the strain rate constant [4].

It should be noted here that the model parameters identification was made for $B, n$ and $C$ constants, whereas a value of $A$ was estimated on the base of quasi-static compression test. Moreover, the procedure of finding parameters was performed on three experimental stressstrain curves, which were obtained for strain rate range of $1200 \div 3000 \mathrm{~s}^{-1}$. The best sets of J-C parameters were the result of the compromise between fitting errors determined for all selected experimental curves. Values of J-C material constants for B500SP and 18G2-b steels are presented in Table 2.

In order to illustrate the convergence of obtained results, the experimental flow stress curves for both steels at various strain rates was compared in Fig. 6 with flow stress data generated using the $\mathrm{J}-\mathrm{C}$ constitutive equation with identified constants. It can be seen from this figure that flow stress computed using $\mathrm{J}-\mathrm{C}$ model is in a satisfactory agreement with experimental data both in the case of B500SP steel and 18G2-b.

\section{Summary}

Dynamic stress - strain curves in compression of tested both steels were obtained by split Hopkinson pressure bar using a pulse shaper technique. The effects of strain rate on mechanical properties of those materials were also briefly addressed. The parameters of material JohnsonCook model was identified by these results. Those two steels exhibit similar strain hardening as well as strain rate hardening.

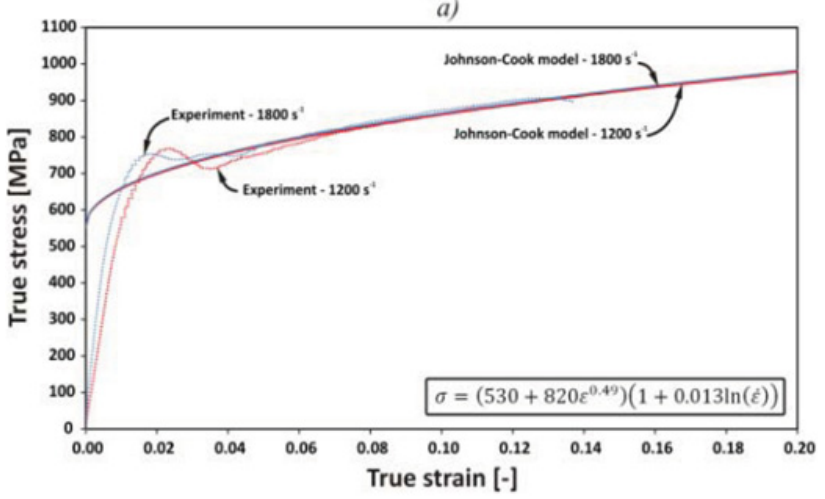

b)

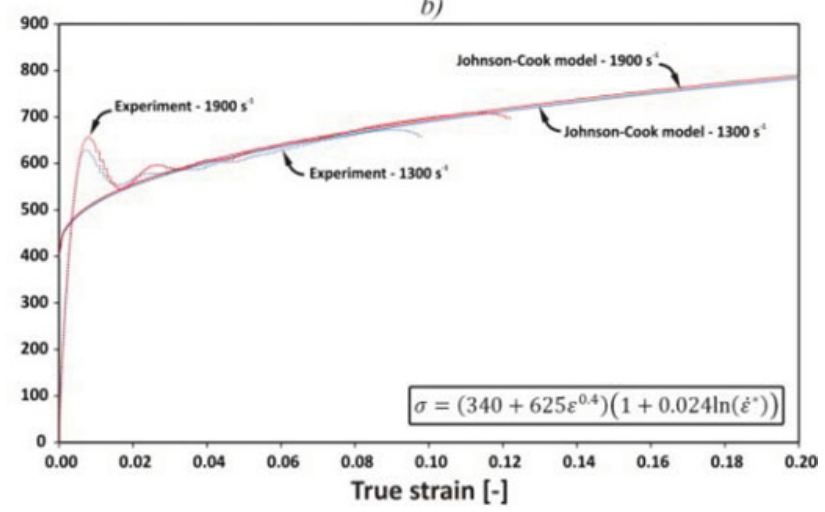

Figure 6. Comparison of Johnson-Cook model predictions with selected experimental results for B500SP (a) and 18G2-b steel (b).

The authors thank to Mr Jakub Bolanowski for his assistance in this work.

\section{References}

[1] M.A. Meyers, Dynamic Behaviour of Materials (Johns Wiley and Sons, INC, New York-ChichesterBrisbane-Toronto-Singapoure, 1994).

[2] J.A. Zukas, ed., High-Velocity Impact Dynamics (Wiley, New York, 1990).

[3] L. Kruszka, R. Rekucki, Applied Mechanics and Materials, 82 (2011).

[4] G.R. Johnson, W.H. Cook, Proceedings of the $7^{\text {th }}$ International Symposium on Ballistics, The Hauge, The Netherlands, April (1983). 